\title{
E-Learning: Boon or Bane to Higher Education during COVID-19 at MENA Region
}

\author{
Dr. Sharif Abu Karsh \\ Associate Professor, Faculty of Administrative and Financial Sciences, Arab American University, Palestine \\ E mail: sharif.abukarsh@aaup.edu
}

\begin{abstract}
The sudden effect of the corona pandemic in many nations has seriously harmed the physical, social, and mental well-being and the global economy. Higher education is the bedrock of every nation that the Pandemic has ravaged. The entire educational system has unexpectedly moved to digital, creating a serious challenge for both students and teachers to adapt to. Is it a challenge, a boon, or a bane for counties in the MENA region to have their higher education systems turned upside down? The complexities of online education will be discussed in this report. The study employed qualitative techniques, which were accomplished through desktop review. The result indicates that eLearning is both boon and bane on higher education in countries in the MENA region. As a result, we can conclude that the eLearning education system should be geared up, and internet accessibility in the MENA region should be strengthened.
\end{abstract}

Keywords - E-Learning; COVID-19; Bane; Boon; Mena; Impacts of COVID-19.

\section{Introduction}

As countries close their borders and quarantine people due to the coronavirus 19 pandemic, a new education system is emerging worldwide (Hechinger \& Lorin, 2020). Many other countries, especially in the Middle East and North Africa (MENA) region, have already begun a distance learning system. Students take lessons and take tests while staying at home. The virus's bane is thought to be an ultimate boon in bridging the much-needed digital divide, as it comes with technologies that introduce new ideas to the MENA region's education system (Mishra, Gupta, \& Shree, 2020). Most MENA countries' governments launched interactive applications for students to learn at home to fight the virus's spread in the region. The World Economic Forum (WEF), based in the Middle East and North Africa (MENA), estimates that 150 million students in the region have access to learning materials through live television broadcasts and e-learning. Millions of students have been forced into temporary homeschooling situations due to these risk-control decisions, especially in some of the most heavily impacted countries in the MENA region, such as Russia and Iran (ShamirInbal, \& Blau, 2021). There is no doubt that these developments have caused some inconvenience, but they have also inspired new educational creativity examples in the Middle East and North Africa. Therefore, this paper seeks to determine whether it is Boon or Bane to Higher Education during COVID 19 at MENA Region.

\section{Methodology}

The report used qualitative analysis methods, which was accomplished by a systematic desktop review to gather relevant information. The desktop analysis was carried out using various search engines, such as Google Scholar, and libraries, such as Willy's online library, to perform an automated and systematic search of relevant scholarly academic articles. Various educational journals, management journals, psychological journals, E-books related to the research subject, and open blogs were reviewed. The following were some of the main search phrases: COVID19, MENA, impacts of COVID19, public health, e-learning, bane, boon, MENA, impacts of COVID19, and high learning institutions. Following that, sources that provided helpful information for the impact of covid19 on education were filtered for inclusion, while those focused more on hypotheses were filtered out.

The study looked at qualitative and quantitative research articles that focused on how the covid19 Pandemic affected education. For analysis, the research papers with the highest evidence rating were selected. Both published and unpublished papers restricted to the English language were checked for the sake of inclusivity. Following a preliminary topic review, the terms captured in the abstract of the index term used to characterize the paper were evaluated. Then there was a thorough search using the key terms highlighted above. Before being included in the final analysis, the papers were analyzed for methodological accuracy. In the final study, papers of various types were used, including quantitative, qualitative, and contextual papers. All information collected from different sources was adequately acknowledged and referenced to ensure that the study's ethical issues were not jeopardized. The paper used the most recent published articles and journals to ensure validity and reliability.

\subsection{Research Problem}

Technology use has been on the rise in the $21^{\text {st }}$ century whereby most organizations use it in making transactions

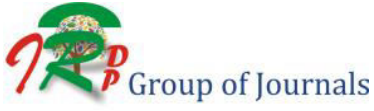


such as payment, conferencing and doing research and development. In the same sense the education sector has embraced the use of technology in form of eLearning, whereby learners do not need to participate in physical classes but can attend remotely. In focusing on the Middle East and North Africa Countries, there is a huge disparity in consumption of eLearning technology in the countries living in this region. This disparity is mostly attributed to unequal distribution of resources and knowhow. In this period of Covid 19 pandemic, countries have embraced this technology in learning because of minimizing social interactions. Because of the increasing quest for knowledge, some countries in the region have implemented eLearning at a significant percentage while others are unable to implement technology and have stuck in the traditional literacy acquisition that only focuses on one's ability to read or write. With this knowledge only, it becomes hard for learners in these regions to compete in acquiring and showcasing skills in the contemporary world.

\section{Literature Review}

Innovators in education have done numerous experiments on digital classrooms for years now since the invention of the internet but the pace has been slow (Sihem, 2018). According to Sihem (2018), e-learning in the Middle East has been slow, frustrating the effort to improve the education system through advancement in technology. However, Global challenges, such as COVID19 , forcing universities to adapt their instructional formats, create their methods and modify them regularly (Hechinger \& Lorin, 2020). As a result, global higher education has become increasingly important in the face of global technological change, notably in the COVID 19 pandemic (Johnson, Veletsianos, \& Seaman, 2020). According to Drucker (1999), the information society and the age of technology are sweeping global higher education into a future where learning how is more important than knowing what.

Research by (Naciri, Baba, Achbani, \& Kharbach, 2020) shows that e-learning compromised the standard of quality assurance in many learning institutions worldwide, particularly the MENA region. After the COVID-19 outbreak, almost all global institutions of higher learning have turned to online learning as the most logical way for students to continue their education (Naciri et al., 2020). This transition happened dramatically in a matter of days, with little time to prepare, forcing institutions and students to adopt new teaching and learning methods and technology at a breakneck pace, using learning management systems, course websites, and interactive resources for online learning (Ferri, Grifoni, \& Guzzo, 2020). In terms of students and the institution, was the transition a success (Lai \& Bower, 2019? The question remains unanswerable as the research continues in the same field to establish sustainable learning programs in the future.

Institutions are being asked to focus more on studentcentered learning, online teaching techniques, and knowledge access developments during COVID-19 (Unger \& Meiran, 2020). COVID-19 has unintentionally succeeded in implementing online learning systems that use, substitute, or exploit conventional teaching and learning methods (McCormack, Lemoine, and Richardson, 20). In a disruption period, online learning has changed the emphasis from alternative learning approaches to key processes for pursuing education (Patra \& Sahu, 2020).

Research by Chang \& Fang (2020) demonstrates that e-learning has caused dramatic disruption in China's education sector, and more so during the COVID-19 epidemic. This has seen institutions of higher learning in the country coordinating the most extensive e-learning programs to meet the requirements to ensure continuity of learning and teaching after disruption as a result of COVID-19. As a result, courses are now covered in the shortest time possible. This is a fast solution to curb the epidemic, but it is challenging to tutors who are used to physical teaching. This evidence demonstrates the enormous challenge of adopting and implementing elearning in China and worldwide, particularly in the MENA region.

\subsection{Types of E-Learning}

Some of the e-learning methods in place today in different institutions include;

- Computer based learning, whereby computers replace the traditional classroom setting to learners using technology. In this, learning materials are stored in the memory devices such as the CD_ROM and DVDs, inserted in computers and the contents can be accessed at any time even if there is no internet connection. In this type of learning, there is use of videos, animations, images and demonstrations that can be easily shared among learners to read at later dates (Raju, 2019).

- Web-based learning requires learners to learn through the internet, where computers and internet connection are installed in designated computer laboratories. In this case, there are sessions of learning computer classes and students can do independent and group researches through searching the internet (Raju, 2019). Through internet classes, students can review numerous online resources from different organisations and writers. The method is flexible and easy to learn and interact.

- Mobile learning is a type if eLearning that involve the use of mobile devices to access the learning materials. The devices might include smartphones, tablets and 
laptops. This requires internet connection to access the learning materials remotely or can share the materials through storage devices (Raju, 2019). Mobile learning is essential as it is not limited to space, as the learners can continue learning even when they are moving, hence the name mobile learning. With mobile learning, it possible to offer virtual classes as long as there is internet connection. This method is widely used especially in times like this the world is experiencing limitation of movement and gathering due to covid 19. This technology would be very effective in the MENA region if it can be fully implemented as it allows innovation, learning and development and sharing of knowledge.

\subsection{Statistical Data}

E-Learning was embraced in large percentage in different countries during the covid 19 pandemic outbreak. Statistics show that eLearning is done through online (internet) and broadcasting through TVs and radio. This is demonstrated in the figure below.

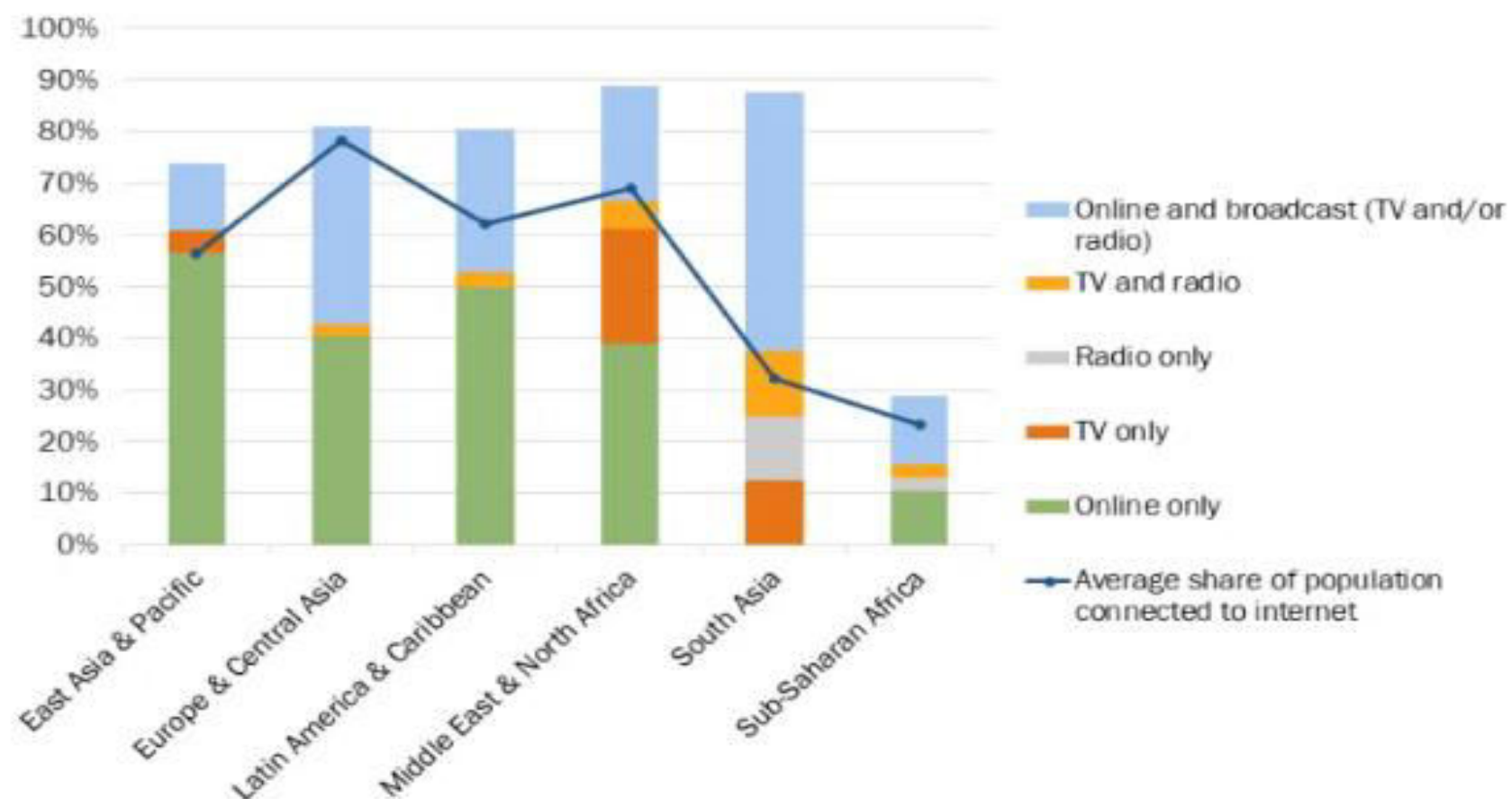

Fig. 1: Share of countries responding to school closures with different forms of remote learning by region

From the above statistics, it is clear that the MENA region is competitive in terms of offering online education with about 60 percent embracing the use of online platforms. In the Middle East and North Africa, those who rely on the use of radio and television account for about 28 percent, and below 40 percent use the internet in online education (Vegas, 2020). about 22 percent of users in the region combine both the online and the broadcast media. with the increased campaign for the use of internet and online learning, it is expected that these figures will increase in the region.

\section{Result and Discussion}

From the analysis of the above literature, it is evident that there has been boon and bane in the higher learning institution due to e-learning programs in the MENA region. The research indicated that embracing digital learning has been slow due to poor reception by learners and tutors. The COVID-19 outbreak, according to experts, has hastened the process. It has been observed that learners and teacher providers fully embrace digital education in various formats as $5 \mathrm{G}$ technology gets increasingly accessible in countries such as, the United States, China, and Japan (Chang, \& Fang, 2020). New learning modalities, such as live streams, educational influencers, and virtual reality experiences, can supplement conventional in-person classroom learning. In China for instance, the Ministry of Education has established a new platform for broadcasting leaning and hosted on cloud that enables students to log in from anywhere (Škavić, 2020).

Further, results indicate that there are several challenges in implementing the education system reform phase that has emerged due to the COVID-19 crisis. Due to the COVID-19-induced period, e-learning has become a

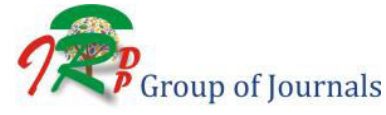


huge challenge as not all stakeholders in the MENA region are technologically capable of adapting to the sudden educational transition. This indicates that, indeed, elearning was a bane to higher education in the MENA region.

Like elsewhere across the globe, eLearning has been adopted as a feasible alternative within its limits for meeting the educational demands under the COVID-19 Pandemic in the MENA region. However, it is debatable if it will be a boon or bane in the future. It has recently proven useful in assessing student results, and at the same time, bane due to its complexity. It can take time to understand how e-learning satisfies the need for net balancing of aggregate consequences in the MENA region. There is a need to close the disparity between the students' studying in remote and urban areas, in using the same pedagogical method for students from different socioeconomic backgrounds. But, since e-learning is still in its infancy in the MENA region, a lack of understanding of students' differences can lead to biased conclusions and make it controversial to determine whether eLearning is a boon or bane higher education in the MENA region.

\section{Conclusion and Recommendations}

\subsection{E-Learning as Bane}

Limited mobility has led to many countries taking their services including education online due COVID-19 lockdown, Education liberalization, privatization, and globalization have all suffered significant setbacks. With disparities in technologies and lack of funding, the MENA region countries face paralysis in policies in coping with abrupt education planning and running of institutions during the COVID-19 Pandemic. developing countries in this region will suffer the most setbacks as they were already running out of financial resources. However, everyone must learn to cope with and survive the current crisis because it is just the beginning; no one can afford to ignore digital transformation in the long run.

\subsection{E-Learning as Boon}

The study intended to determine whether Boon or Bane to Higher Education during COVID 19 at MENA Region. The evidence from the above discussion has indicated that it is a bane to higher education amid covid19 at the MENA. It is a bane since the covid19 has resulted in severe disruption in the education system, jeopardizing almost all learning institutions' learning process. For instance, the lockdown and crossing borders led to institution closing. On the other hand, the Pandemic has given an opportunity and a lesson that it is crucial to bridge the digital gap and offer skills to create resistance to threats ranging from natural disasters to abuse in an unpredictably shifting environment. More specifically, it necessitates adaptability so that resilience can be integrated into the most critical field, the educational system. In a nutshell, it is both a blessing and a bane to Higher Education in the MENA Region during COVID 19.

\subsection{Recommendations}

It has been suggested that governments and corporations in the MENA region reduce costs and make digital classrooms available to the less well-off students who cannot afford to buy digital devices. If not so, the digital divide might continue to expand much further. The apprehension stems from the fact that only about $60 \%$ of the world's population has access to the internet. Benchmarking from China, evidence indicates that a coalition of professionals from more than 60 firms came together in Hong Kong to offer 900 educational assets such as videos, book chapters, evaluation resources, and counseling services - to students studying at home for free (Škavić, 2020). Most schools in impacted areas seek workarounds to keep teaching going, but the standard of learning heavily depends on digital access level and quality. Further, this paper suggests that institutions in the MENA region should invest heavily in improving e-learning infrastructure to ensure synchronous instruction and elearning literacy, developing e-learning content, and building capacity to address all of the challenges. Perhaps this will curb the resulting bane of e-learning in the region while enjoying the boon.

\section{Reference}

[1] Binti Shahidan, N., Binti Ariffin, N., Ishak, M. F. H., \& bin Sabilan, S. Online Teaching: Readiness Among Lecturers In Higher Learning Institutions. [Retrieved from Google Scholar] http://conference.kuis.edu.my/ispen/wpcontent/uploads/2020/12/ISP EN20_23.pdf

[2] Chang, C. L., \& Fang, M. (2020, June). E-Learning and online instructions of higher education during the 2019 novel coronavirus diseases (COVID-19) epidemic. In Journal of Physics: Conference Series (Vol. 1574, No. 1, p. 012166). IOP Publishing.

[3] Drucker, P. F. (1999). Beyond the information revolution. The Atlantic Monthly, 284(4), 47-57

[4] Ferri, F., Grifoni, P., \& Guzzo, T. (2020). Online Learning and Emergency Remote Teaching: Opportunities and Challenges in Emergency Situations. Societies, 10(4), 86

[5] Hechinger, J., \& Lorin, J. (2020, March 19). Coronavirus forces $\$ 600$ billion higher education industry online." Bloomberg BusinessWeek,. [Retrieved from Google Scholar] https://www.bloomberg.com/news/articles/2020-03-19/colleges-aregoingonline-because-of-the-coronavirus

[6] Johnson, N., Veletsianos, G. \& Seaman, J. (2020). US faculty and administrators' experiences and approaches in the early weeks of the COVID-19 Pandemic. Online Learning, 24(2), 6-21.

[7] McCormack, T. J., Lemoine, P. A., \& Richardson, M. D. (2020b). Online teaching and learning in global higher education during COVID-19. International Education and Research Journal, 6(10), 33-35. 
[8] Mishra, L., Gupta, T., \& Shree, A. (2020). Online teaching-learning in higher education during lockdown period of COVID-19 Pandemic. International Journal of Educational Research Open, 1, 100012.

[9] Naciri, A., Baba, M. A., Achbani, A., \& Kharbach, A. (2020). Mobile learning in higher education: Unavoidable alternative during COVID-19. Aquademia, 4(1), ep20016.

[10] Patra, S., \& Sahu, K. K. (2020). Digitalisation, online learning and virtual world. Horizon Journal of Humanities and Social Science. 2(S), 45-52.

[11] Raju, P. R. K. (2019). E-learning boon or bane. An HRD perspective. Retrieve on, 24.

[12] Richardson, M. D. (2020). The Impact of Online Learning in Global Higher Education during Covid-19. [Retrieved from Google Scholar]

https://www.academia.edu/download/65886913/02_Michael_D._Ric hardson_Online_IERJ20183252167904.pdf

[13] Shamir-Inbal, T., \& Blau, I. (2021). Facilitating Emergency Remote K-12 Teaching in Computing-Enhanced Virtual Learning Environments during COVID-19 Pandemic-Blessing or Curse? Journal of Educational Computing Research, 0735633121992781.
[14] Sihem, H. (2018). Tunisia. E-Learning in the Middle East and North Africa (MENA) Region, 407-432.

[15] Škavić, F. (2020). Social Impact of Digital Technologies Employed By Countries In The Wake Of The Covid-19 Pandemic (Doctoral dissertation, University of Zagreb. Faculty of Economics and Business. Department of Informatics.).

[16] Sharif M. Abu Karsh (2018).New Technology Adoption by Business Faculty in Teaching: Analyzing Faculty Technology Adoption Patterns, Education Journal. Vol. 7, No. 1, 2018, pp. 5-15.

[17] Unger, S., \& Meiran, W. (2020). Student attitudes towards online education during the COVID-19 viral outbreak of 2020: Distance learning in a time of social distance. International Journal of Technology in Education and Science, 4(4), 256-266

[18] 18. Vegas, E. (2020, April 14). School closures, government responses, and learning inequality around the world during COVID19. Retrieved from brookings.edu: https://www.brookings.edw research/school-closures-government-responses-and-learninginequality-around-the-world-during-covid-19/ 